\title{
Seismic Sequences' Branching Structures: Long-Range Interactions and Hazard Levels
}

\author{
Giulio Riga1, Paolo Balocchi² \\ ${ }^{1}$ Geologist, Independent Researcher, Lamezia Terme, Italy \\ ${ }^{2}$ Geologist, Independent Researcher, Modena, Italy \\ Email: giulio.riga@tin.it
}

How to cite this paper: Riga, G. and Balocchi, P. (2016) Seismic Sequences' Branching Structures: Long-Range Interactions and Hazard Levels. Open Journal of Earthquake Research, 5, 189-205.

http://dx.doi.org/10.4236/ojer.2016.54016

Received: August 30, 2016

Accepted: October 16, 2016

Published: October 19, 2016

Copyright $\odot 2016$ by authors and Scientific Research Publishing Inc. This work is licensed under the Creative Commons Attribution International License (CC BY 4.0).

http://creativecommons.org/licenses/by/4.0/ (c) (i) Open Access

\begin{abstract}
Branching structures can provide early information on earthquakes' preparation process, trigger stage, different breaking patterns that can occur before strong earthquakes and hazard levels reached in the area to be analyzed. In this study, we aim to understand the earthquakes long-range interactions which constitute the nodes of higher order seismic rods in the upper branching structure, and the hazard level reached in each developmental stage as well as to provide a warning time frame for the most energetic seismic events and a sound method to obtain information on the epicentral area. To this end, we have analyzed several branching structures by using both local and global seismicity. The analysis of different branching structures both on global and local scale highlights long-range interactions between the most energetic earthquakes and their triggering by smaller shocks, thus suggesting that the triggering can occur few minutes to decades before the earthquake, depending on a seismic sequence's development speed and its structure.
\end{abstract}

\section{Keywords}

Branching Structure, Earthquake, Microsequence, Hierarchization, Foreshock, Hazard

\section{Introduction}

Several studies show how the aftershocks observed on time scales of minutes to months after a mainshock can be triggered by static and dynamic stresses imparted by the stress change and the mainshock waves' passage [1].

Branching structures [2], associated with earthquakes and their development over time, have proven to be a helpful instrument to obtain crucial information about the occurrence of future events, the interaction between the earthquakes they consist of and 
the local faults' critical and hazard state.

The purpose of this study is to describe the analysis method of seismic sequences in order to locate the nodes of higher order seismic rods in the upper and lower branching structure. Further, by analyzing the seismic sequence and using the nodes in the upper branching structure, we will propose a novel method for identifying the zone within which a future strong earthquake's epicenter may fall.

Through the analysis of the seismic rods in the upper branching structure, we will also introduce a sequence seismic hazard classification in order to define the warning signs during the seismicity's time evolution of the analyzed area.

Finally, the joint analysis of the seismic rods in the upper branching structure allows us to obtain relevant information on possible interactions between different earthquakes on local and global scale, probably due to the effects of the changes caused by static and dynamic stresses.

The analysis of the seismic sequence structure is performed by using: 1) a datasets spatial coverage involving parts of a region or several countries (from a few tens to thousands of $\mathrm{km}$ ), 2) a range of magnitude values of $2.0-10 \mathrm{~m}, 3$ ), a range of depths of $1-50 \mathrm{~km}$.

\section{Method}

\subsection{Upper and Lower Branching Structure}

The sequences of higher order seismic rods in the upper and lower branching structures are patterns that allow the graphical evaluation of the earthquake preparation process's magnitude and therefore contribute to outline the past and future seismicity evolution of an area. These are identified through the consideration that after an energy shock the magnitude values gradually decrease and increase in the upper and lower structure, respectively, up to the Trigger Point (TP) by following a hierarchization process.

The entire preparation time of the upper branching structure can be divided into three stages: 1) energy accumulation, 2) trigger, 3) energy release [2].

Figure 1 shows the patterns of the upper and lower branching structures: as it can be seen, the first developmental stage (the largest) in the upper branching structure starts to develop after a strong earthquake (point source), while the subsequent ones are related to the decrease in the magnitude values over time. In the lower branching structure, however, a trend to increase the magnitude values over time can be observed.

Furthermore, we note a decrease in the recurrence rates or the number of events in the final portion of the branching structures and a common trigger point (TP) determining the transition from the energy accumulation to the energy release stage. The energy release stage develops within a shorter time frame compared to the accumulation stage. The distance between the TP and the mainshock is the warning time frame of an energetic seismic event. Usually, a first warning signal results from the convergence of a third order lower branch with a second order higher one (point A). For example, in the case of the Samoan earthquake on 29 September 2009, a second abnormal 


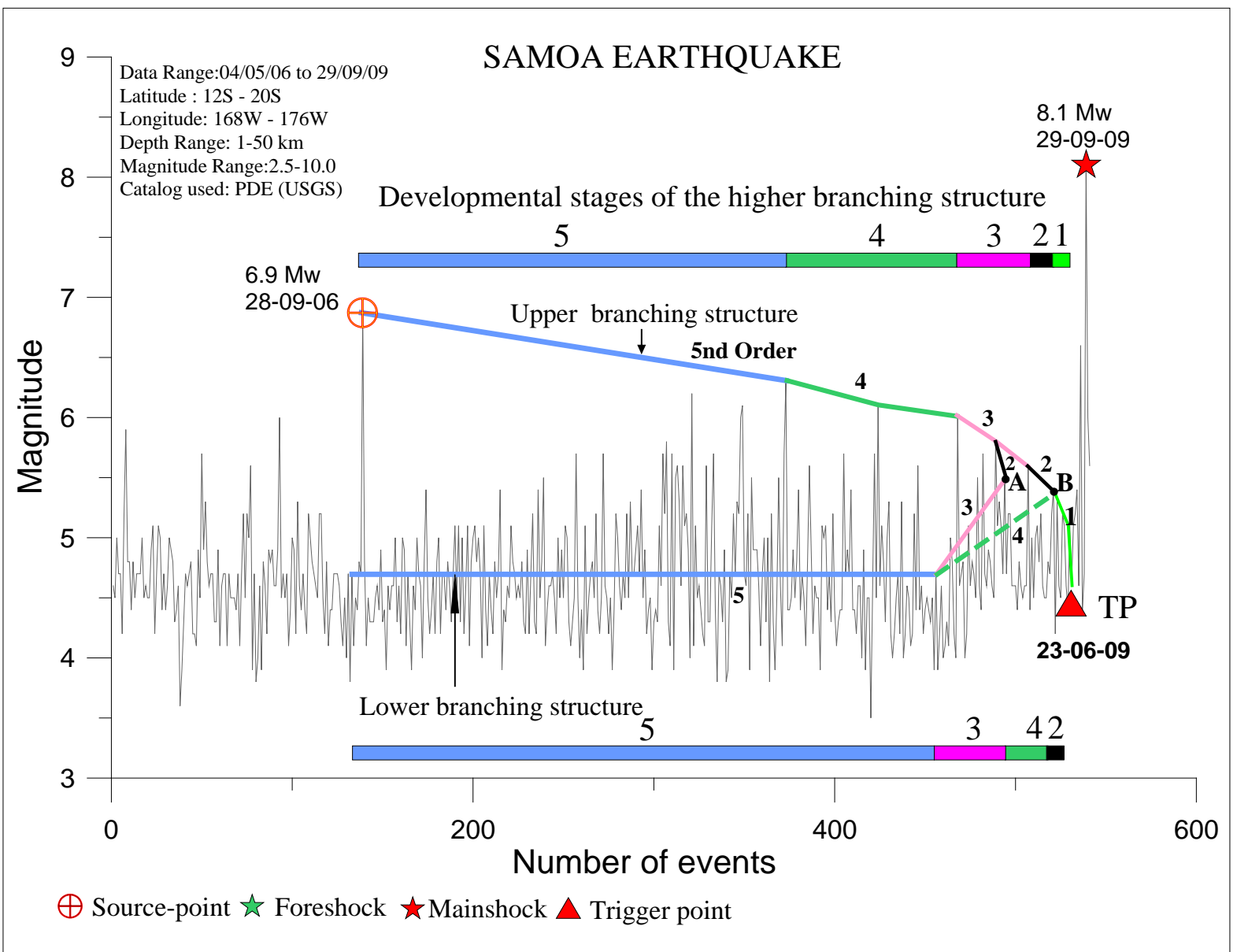

Figure 1. Energy accumulation phase's developmental stages in the upper and lower branching structure. The vertical axis shows the magnitude values, while the horizontal axis displays the number of events recorded in the period analyzed.

warning sign resulted from the convergence of a lower fourth order branch with a higher second order one (point B).

\subsection{Upper Branching Structure Hazardousness}

The classification process provides not only information on the upper branching structure's developmental state, but also a more consistent hazard classification related to the upper branching structure, which can be represented with colors.

The branching structure's hazard level is classified according to the seismic branches magnitude [2], by establishing seven hazard classes ranging from extremely high to low. The different hazard levels were encoded with colors that let us know, in a simple and quick fashion, the critical level reached by the upper branching structure that is being developed in an area either on local or global scale.

We chose the magnitude as a criterion for the division into hazard classes in order to identify the branching structure hazardousness at any point in its evolution.

The branching structures classification process involves several steps, including the following: 
- Upper branching structure detection;

- Identification of the magnitude values of the seismic branches nodes it consists of and of the energy release stage;

- Determining the hazard class of each stage of the energy accumulation and release phases;

- Determining the hazard class of the energy release last stage.

As it uses seven hazard classes, this method can be successfully adopted to determine the appropriate warnings during the energy release stage, which can lead to a strong earthquake.

Table 1 lists the different hazard classes of the upper branching structure per magnitude range, while Figure 2 shows the hazard classes, determined according to the magnitude values of the energy accumulation and release stages during the Samoan earthquake on 29 September 2009.

Initially, we note a gradual reduction of the upper branching structure's hazard level up to the TP, thereafter the hazard rises until it reaches an extremely high value coinciding with the mainshock. The midpoint of the fifth order branch, which defines the alleged value of the expected magnitude [2], enables us to estimate the energy release stage's minimum hazard, which in this case was estimated to be high.

\subsection{Epicentral Area Identification-Aimed Procedure}

This procedure, which can be of help in identifying the epicentral area of a strong earthquake, consists in plotting on a map the nodes' epicenters in the upper branching structure along with the trigger signals. Figure 3 illustrates the position of the nodes' epicenters in the Japan's upper branching structure (Table 2), whose release stage was characterized by two foreshocks measuring $5.7 \mathrm{Mw}$ and 7.3 Mw magnitudes respectively, recorded on 06/12/2010 and 09/03/2011 and by the earthquake occurred on 11 March 2011, with a magnitude of $9.0 \mathrm{Mw}$.

If we observe carefully the map, we will see how the epicenters tend to group over time depending on their type, i.e. nodes' epicenters in the energy accumulation and energy release stages and TP-related ones. One of the epicenters of the shocks which the TP or the energy release stage consists of is almost always close to the mainshock.

Therefore, in order to predict the mainshock epicenter, it is considered more appropriate to use the clusters including the shocks epicenters which the TP or the energy

Table 1. Hazard classes.

\begin{tabular}{ccc}
\hline Class & Magnitude & Hazard \\
\hline 1 & 8 or more High & Extremely High \\
2 & $7-7.9$ & Very High \\
3 & $6-6.9$ & High \\
4 & $5-5.9$ & Moderately High \\
5 & $4-4.9$ & Moderate \\
6 & $3-3.9$ & Moderately Low \\
7 & $1-3.0$ & Low \\
\hline
\end{tabular}


Table 2. Coordinates and magnitude of nodes and warning sign in the upper branching structure of Japan earthquake, 2011.

\begin{tabular}{cccccc}
\hline No Node & Date & Latitude & Longitude & Magnitude & Stage/Node \\
\hline 1 & $19 / 07 / 2008$ & 37.55 & 142.21 & $7.0 \mathrm{Mw}$ & Source-point \\
2 & $14 / 03 / 2010$ & 37.74 & 141.59 & $6.5 \mathrm{Mw}$ & Energy accumulation \\
3 & $04 / 07 / 2010$ & 39.70 & 142.37 & $6.3 \mathrm{Mw}$ & Energy accumulation \\
4 & $29 / 09 / 2010$ & 37.26 & 139.88 & $5.5 \mathrm{Mw}$ & Energy accumulation \\
5 & $10 / 10 / 2010$ & 31.07 & 141.61 & $5.1 \mathrm{mb}$ & Energy accumulation \\
6 & $17 / 10 / 2010$ & 36.39 & 141.18 & $4.8 \mathrm{mb}$ & Energy accumulation \\
7 & $17 / 10 / 2010$ & 30.02 & 130.92 & $4.0 \mathrm{mb}$ & Trigger \\
8 & $19 / 10 / 2010$ & 36.33 & 142.26 & $4.7 \mathrm{mb}$ & Trigger \\
9 & $22 / 10 / 2010$ & 32.39 & 141.39 & $4.2 \mathrm{mb}$ & Trigger \\
10 & $06 / 12 / 2010$ & 40.90 & 142.97 & $5.7 \mathrm{Mw}$ & Foreshock \\
11 & $09 / 03 / 2011$ & 38.44 & 142.84 & $7.3 \mathrm{Mw}$ & Source-point-Foreshock \\
12 & $09 / 03 / 2011$ & 38.30 & 142.81 & $6.4 \mathrm{Ms}$ & Energy accumulation \\
13 & $10 / 03 / 2011$ & 38.60 & 142.27 & $5.6 \mathrm{Mw}$ & Energy accumulation \\
14 & $10 / 03 / 2011$ & 38.05 & 143.30 & $5.2 \mathrm{Mw}$ & Energy accumulation \\
15 & $10 / 03 / 2011$ & 38.53 & 143.04 & $5.2 \mathrm{Mw}$ & Energy accumulation \\
16 & $10 / 03 / 2011$ & 38.49 & 143.11 & $4.7 \mathrm{mb}$ & Trigger \\
17 & $10 / 03 / 2011$ & 38.78 & 143.05 & $4.9 \mathrm{mb}$ & Trigger \\
18 & $11 / 03 / 2011$ & 38.19 & 143.15 & $4.2 \mathrm{mb}$ & Trigger \\
19 & $11 / 03 / 2011$ & 38.30 & 142.37 & $9.0 \mathrm{Mw}$ & Mainshock \\
\hline
\end{tabular}

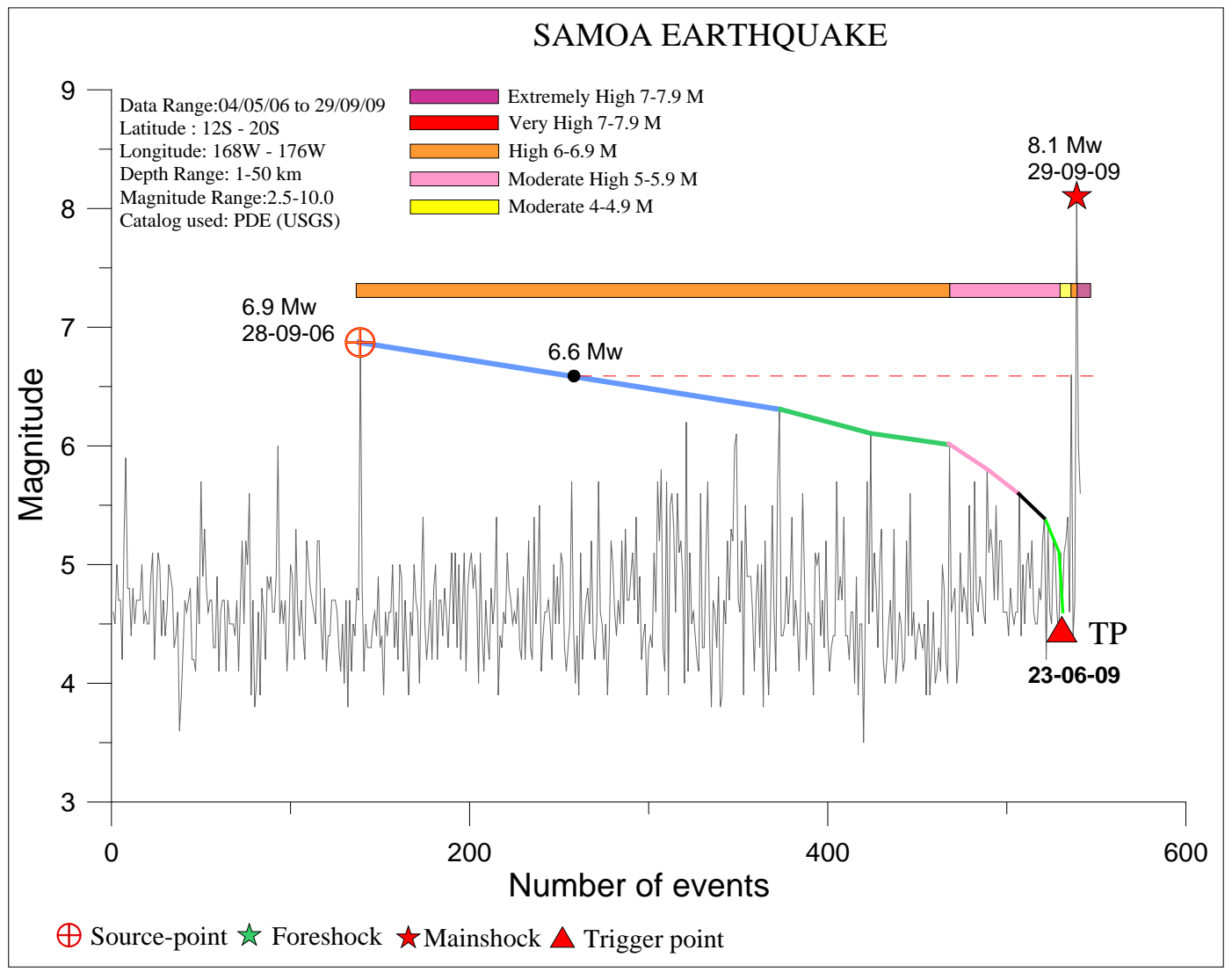

Figure 2. Samoan earthquake. Branching structure and hazard classes. 


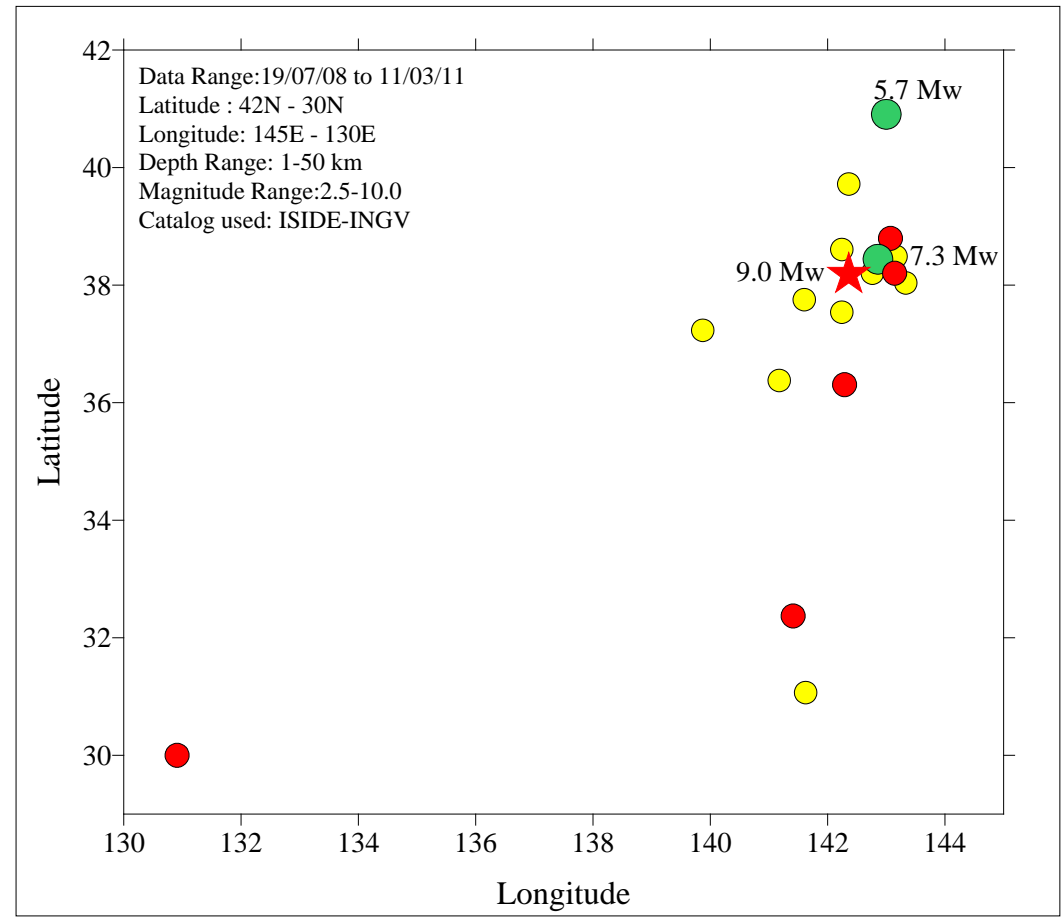

Figure 3. Japan's seismic sequence. Yellow circles: energy accumulation nodes' epicenters; red circles: TP epicenters; green circles: energy release stage epicenters; red star: mainshock epicenter.

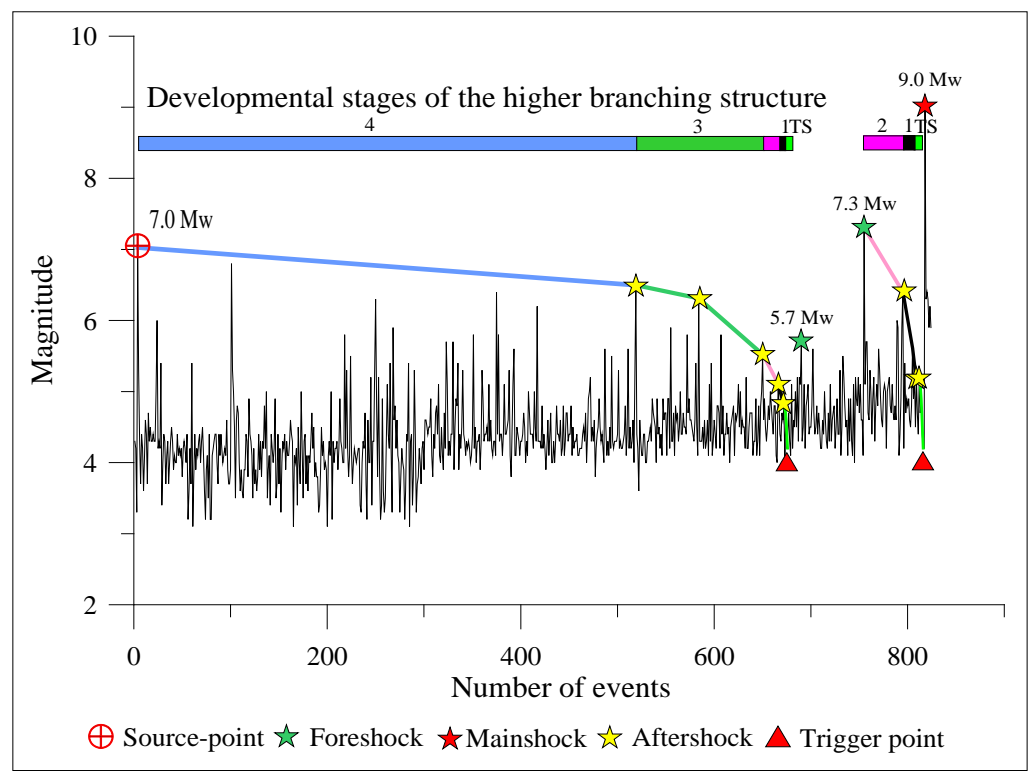

Figure 4. Earthquake's seismic sequence, Japan, 2011, and upper branching structure.

release stage consists of.

Figure 4 shows the seismic sequence and the upper branching structure that preceded the earthquake on 11 March 2011. 


\subsection{Global Scale Branching Structures}

Several earthquakes do not occur as independent events: just as faults' mutual interaction causes a change in the static stress, so too earthquakes can interfere through the dynamic variation of the stress field. The co-seismic stress change, caused by the wave passage, can lead to a seismicity increase even in some portions of the areas far from the mainshock, while in the neighbouring areas we can detect a seismicity quiescence resulting from the stress drop. A large number of studies describe the interference between earthquakes [3]-[5].

After a major seismic event, we observe the development of aftershocks, which generally may occur over a short period of time, due to the dynamic stresses associated with the passage of seismic waves produced by the main shock. Medium-long term aftershocks may develop, which are associated with changes in the static stress [1] [6] [7].

In general, dynamic stresses can trigger long distance aftershocks, even more than $10,000 \mathrm{~km}$, where the stress caused by the passage of the mainshock seismic wave, affects the crustal deformation by disrupting the crossed medium's elastic properties change [3] [8] [9]. Static stresses have a greater influence in the regions closest to the mainshock [3] [6] [10].

The stress changes induced by static stresses, can anticipate or delay a series of aftershocks depending on the sign associated to the stress variation [6] [10], while the trigger produced by dynamic stresses, linked to the medium's elastic variation, is capable of generating seismic events following the main one [11].

The branching structure's long-term development [2] can provide important clues related to future events' occurrence. In addition, the analysis of the branching structure suggests that the triggering of other earthquakes can occur after a mainshock, in areas where faults may be in a state of critical stress.

Below we analyze on global scale the upper branching structure of two recent strong earthquakes in order to obtain information on the interaction between the most energetic earthquakes and the energy accumulation and release stage in the upper branching structure. From our studies we infer that the delays due to the co-seismic stress changes' application depend on the branching structure developmental stage.

We note a delays decrease in the final portion of the branching structure and during the energy release stage, while the different time-scales observed in the higher order branches most likely reflect different tectonic loading rates in the regions.

Figure 5 shows the branching structures of the Ecuador earthquake. The energy accumulation stage that developed after the 6.9 Mw earthquake occurred on 03 April 2016 (point source) consists of eight seismic events featuring a decreasing magnitude over time and delays between them ranging from a few hours to a maximum of 3 days (Table 3). The TP formed on 13/04/2016 with a delay of about 3 days compared to the mainshock. The energy release stage was "Progressive earthquakes"-type and consisted of 4 foreshocks of increasing magnitude and one mainshock [12]. The foreshocks straight interpolation line (red dashed line) has enabled us to make a preliminary estimate of the mainshock magnitude, while the minimum magnitude, calculated from the 


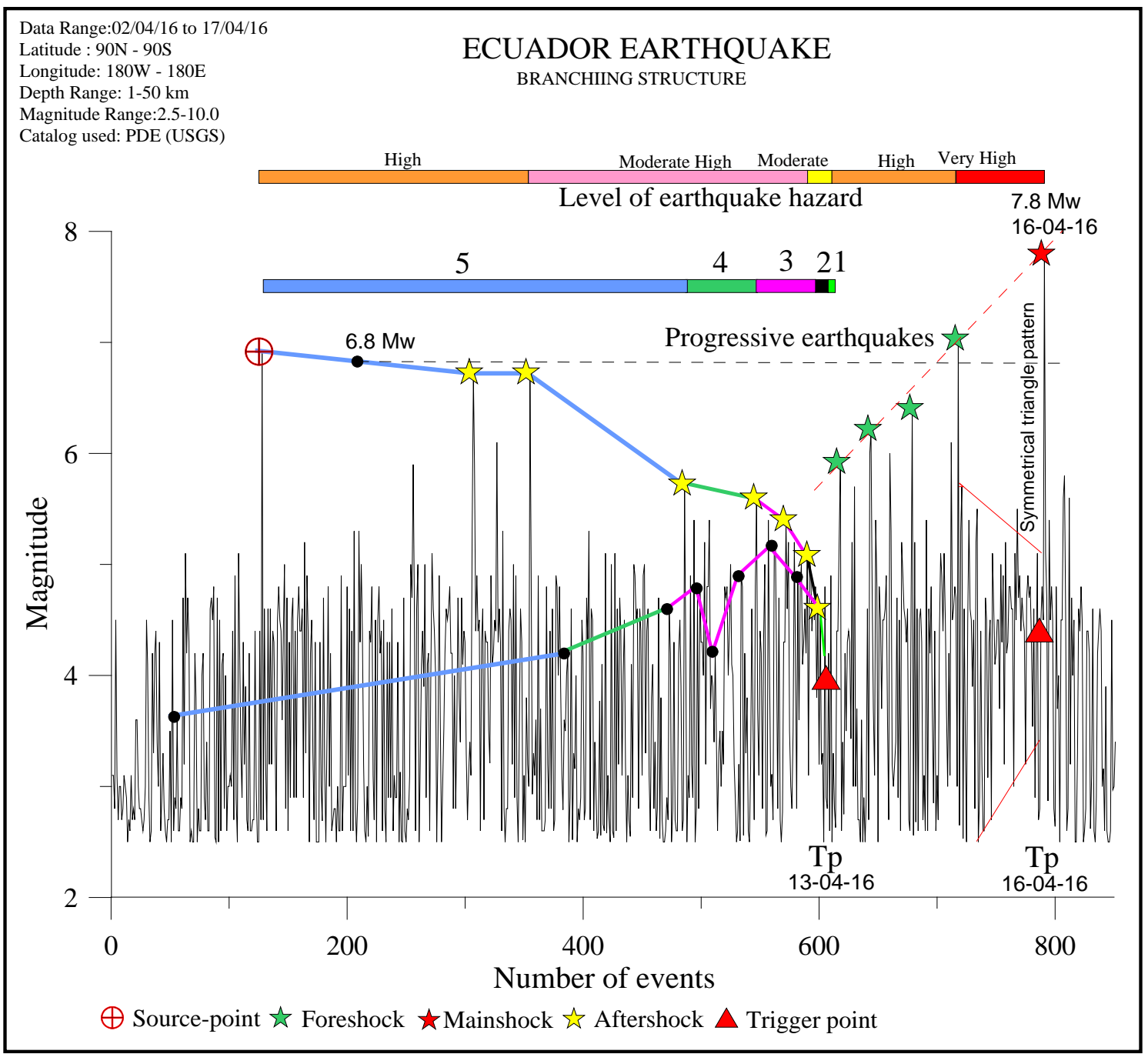

Figure 5. Ecuador earthquake. Branching structures and hazard classes.

Table 3. Coordinates and magnitude of the nodes and the warning signal in the 2016 Ecuador earthquake's upper branching structure.

\begin{tabular}{cccccccc}
\hline No Node & Date & Time & Latitude & Longitude & Magnitude & Delay & Stage/Node \\
\hline 1 & $03 / 04 / 2016$ & $08: 23: 52$ & -14.3235 & 166.8551 & $6.9 \mathrm{Mw}$ & - & Source-point \\
2 & $06 / 04 / 2016$ & $06: 58: 48$ & -14.0821 & 166.5981 & $6.7 \mathrm{Mw}$ & $3 \mathrm{~g}$ & Energy accumulation \\
3 & $07 / 04 / 2016$ & $03: 32: 53$ & -13.9805 & 166.5943 & $6.7 \mathrm{Mw}$ & $1 \mathrm{~g}$ & Energy accumulation \\
4 & $10 / 04 / 2016$ & $02: 14: 34$ & -4.1625 & 102.2024 & $5.7 \mathrm{Mw}$ & $3 \mathrm{~g}$ & Energy accumulation \\
5 & $11 / 04 / 2016$ & $20: 10: 35$ & 51.8428 & 176.6228 & $5.6 \mathrm{mb}$ & $1 \mathrm{~g}$ & Energy accumulation \\
6 & $12 / 04 / 2016$ & $03: 22: 48$ & -3.7177 & -103.9077 & $5.4 \mathrm{mb}$ & $1 \mathrm{~g}$ & Energy accumulation \\
7 & $12 / 04 / 2016$ & $23: 22: 58$ & 11.3235 & 140.8509 & $5.1 \mathrm{mb}$ & $0 \mathrm{~g}$ & Energy accumulation \\
8 & $12 / 04 / 2016$ & $23: 40: 48$ & 11.3791 & 140.9720 & $4.7 \mathrm{mb}$ & $0 \mathrm{~g}$ & Energy accumulation \\
9 & $13 / 04 / 2016$ & $01: 35: 05$ & -14.4136 & 166.5495 & $4.6 \mathrm{mb}$ & $1 \mathrm{~g}$ & Energy accumulation \\
10 & $13 / 04 / 2016$ & $06: 34: 35$ & 63.0259 & -151.7138 & $2.5 \mathrm{M} \mathrm{L}$ & 0 & Trigger \\
\hline
\end{tabular}


midpoint of the first seismic branch, is estimated to be $6.8 \mathrm{Mw}$ (black dashed line). The trigger pattern preceding the mainshock was "Symmetrical triangle"-type [12].

The hazard level of the upper branching structure shows a decreasing trend from high to moderate while after the TP it reaches very high values just before the mainshock. The achieved results make us assume a remote interaction between different faults stressed by the seismic waves generated by the most energetic branching structure's earthquakes.

Figure 6 shows the location of strongest earthquakes epicenters in the energy accumulation (yellow stars) and release (green and red stars) stage and of the three shocks the trigger point consists of (red-brown stars).

It appears that the epicenter of one of the three TP's shocks is located near the mainshock, while the energy accumulation and release stages have developed far from the epicenter.

A similar developmental pattern is shown by the Nepal earthquake's branching structures (Figure 7).

The energy accumulation stage that developed after the earthquake on 17 April 2015 (point source) consisted of six earthquakes with decreasing magnitude over time and with delays ranging from a few hours to a maximum of 3 days (Table 4). The TP formed on 23/04/2015 with a delay of about 2 days compared to the mainshock. The energy release stage, consisting of 4 foreshocks of increasing magnitude and one mainshock, was "Progressive earthquakes"-type [12]. The foreshock straight interpolation

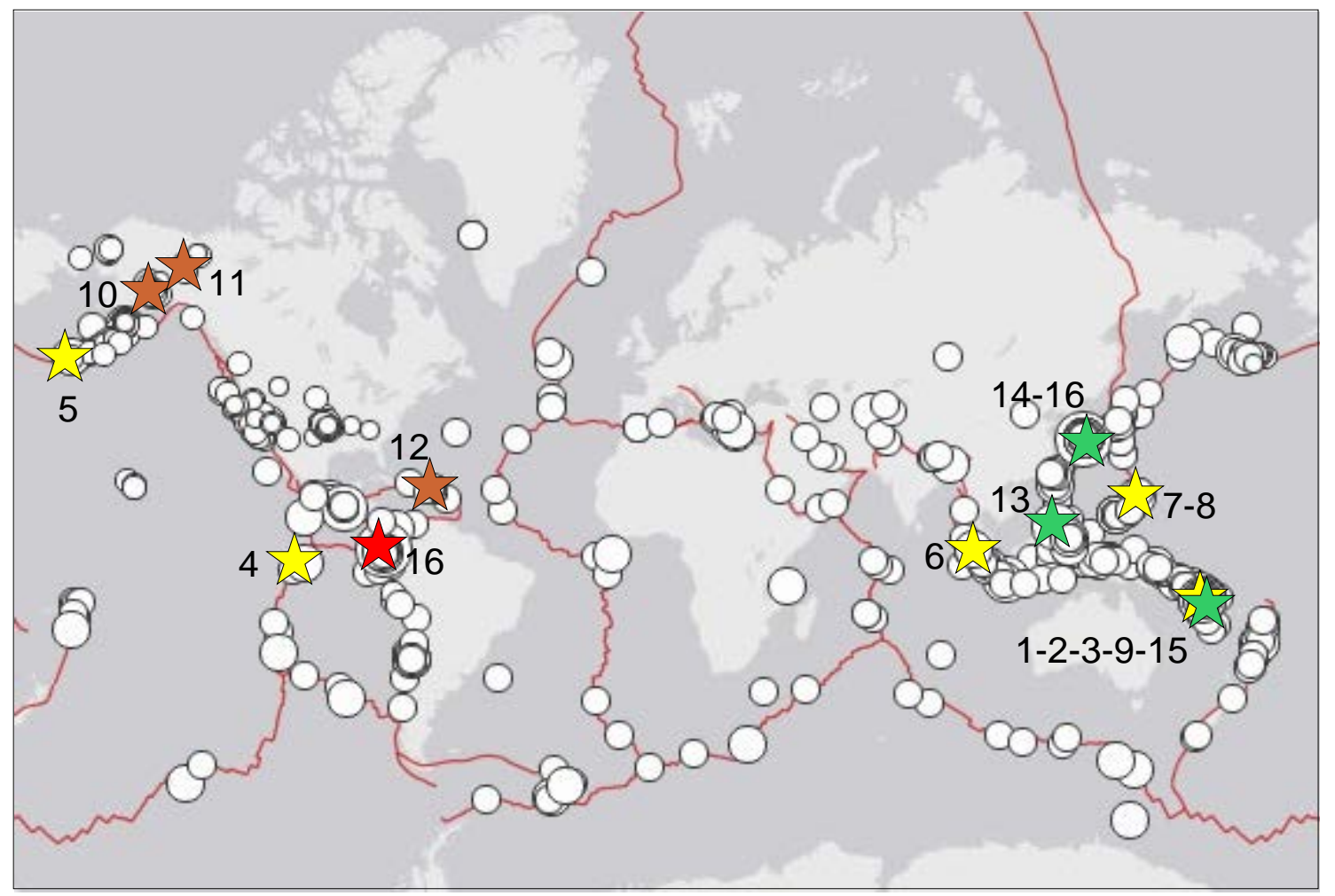

Figure 6. Ecuador earthquake. Earthquakes epicenters of the upper branching structure and TP. 


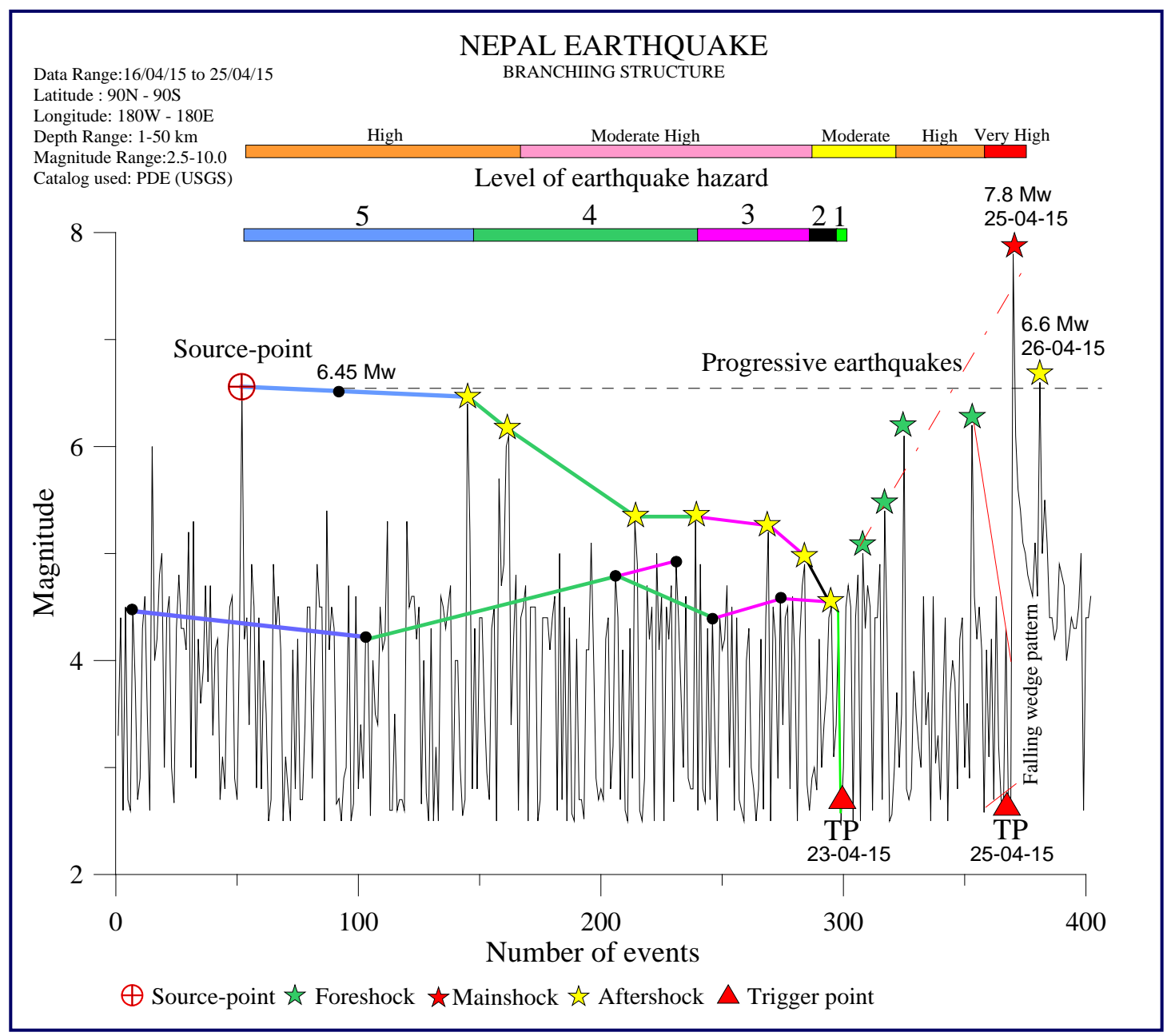

Figure 7. Earthquake in Nepal. Branching structures and hazard classes.

Table 4. Coordinates and magnitude of the nodes and the warning signal in the upper branching structure of Nepal 2015 earthquake.

\begin{tabular}{cccccccc}
\hline No Node & Date & Time & Latitude & Longitude & Magnitude & Delay & Stage/Node \\
\hline 1 & $17 / 04 / 2015$ & $15: 52: 51$ & -15.8815 & -178.6005 & $6.5 \mathrm{Mw}$ & - & Source-point \\
2 & $20 / 04 / 2015$ & $01: 42: 58$ & 24.2026 & 122.3158 & $6.4 \mathrm{Mw}$ & $3 \mathrm{~g}$ & Energy accumulation \\
3 & $21 / 04 / 2015$ & $11: 21: 09$ & -6.0966 & 149.8353 & $5.3 \mathrm{Mw}$ & $1 \mathrm{~g}$ & Energy accumulation \\
4 & $21 / 04 / 2015$ & $19: 10: 15$ & -6.3348 & 154.7629 & $5.3 \mathrm{Mw}$ & $0 \mathrm{~g}$ & Energy accumulation \\
5 & $22 / 04 / 2015$ & $17: 03: 12$ & -30.6629 & -178.3427 & $5.2 \mathrm{Mw}$ & $1 \mathrm{~g}$ & Energy accumulation \\
6 & $22 / 04 / 2015$ & $23: 07: 30$ & -31.4858 & 76.7845 & $4.9 \mathrm{mb}$ & $0 \mathrm{~g}$ & Energy accumulation \\
7 & $23 / 04 / 2015$ & $08: 31: 04$ & -33.2693 & -179.2935 & $4.5 \mathrm{mb}$ & $1 \mathrm{~g}$ & Energy accumulation \\
8 & $23 / 04 / 2015$ & $10: 39: 27$ & 53.8161 & -163.8865 & $2.5 \mathrm{ML}$ & $0 \mathrm{~g}$ & Trigger \\
9 & $23 / 04 / 2015$ & $10: 15: 18$ & 0.5147 & 92.2925 & $4.4 \mathrm{Mb}$ & $0 \mathrm{~g}$ & Trigger \\
10 & $23 / 04 / 2015$ & $09: 02: 13$ & 57.9079 & -142.9024 & $3.1 \mathrm{ML}$ & $0 \mathrm{~g}$ & Trigger \\
11 & $23 / 04 / 2015$ & $14: 57: 27$ & 51.7501 & 176.3353 & $5.0 \mathrm{Mw}$ & $0 \mathrm{~g}$ & Foreshock \\
12 & $24 / 04 / 2015$ & $01: 34: 55$ & 40.4556 & -127.1509 & $5.4 \mathrm{Mw}$ & $1 \mathrm{~g}$ & Foreshock \\
13 & $24 / 04 / 2015$ & $03: 36: 42$ & -42.0602 & 173.0066 & $6.1 \mathrm{Mw}$ & $0 \mathrm{~g}$ & Foreshock \\
14 & $24 / 04 / 2015$ & $13: 56: 15$ & 51.6148 & -130.7714 & $6.2 \mathrm{Mw}$ & $0 \mathrm{~g}$ & Foreshock \\
15 & $25 / 04 / 2015$ & $06: 11: 25$ & 28.2305 & 84.7314 & $7.8 \mathrm{Mw}$ & $1 \mathrm{~g}$ & Mainshock
\end{tabular}


line (red dashed line) allowed us to calculate with sufficient accuracy mainshock's, while the minimum magnitude, which was estimated to be $6.45 \mathrm{Mw}$, was calculated from the midpoint of the first seismic branch (black dashed line). The breaking pattern preceding the mainshock was "Falling wedge"-type [12].

The upper branching structure hazardousness shows a decreasing trend from high to moderate while after the TP it reaches very high values just before the mainshock.

In Figure 8 we can note how the epicenter of one of the three TP shocks (red-brown stars) is located close to the mainshock (red star), while the energy accumulation (yellow stars) and release (green stars) stages have developed away from the epicenter.

\subsection{Examples of Branching Structures}

The examples shown in Figures 9-12 display the main branches in the upper and lower branching structures that have developed before some strong earthquakes as well as the branching structure's hazard classes developed over time.

The branches in the two branching structures, identified with the long-term seismic sequence hierarchization method, highlight how they tend to converge over time to generate the TP, which in some cases is followed by various order warning signs [13]. The TP may be followed by "Flash earthquake"-type (Figure 9 and Figure 10) [12] or "Progressive earthquakes"-type (Figure 11 and Figure 12) energy release stages.

The upper branching structure hazard level tends to decrease from the point source up to TP, then sharply increase up to the main event.

The alternation of the various seismic branches in the upper and lower branching structures show a repetitive development that can be used to obtain information on the seismic sequences' developmental state. In fact, it is clear that the formation of a certain order branch in the upper branching structure is subsequent to the formation of a

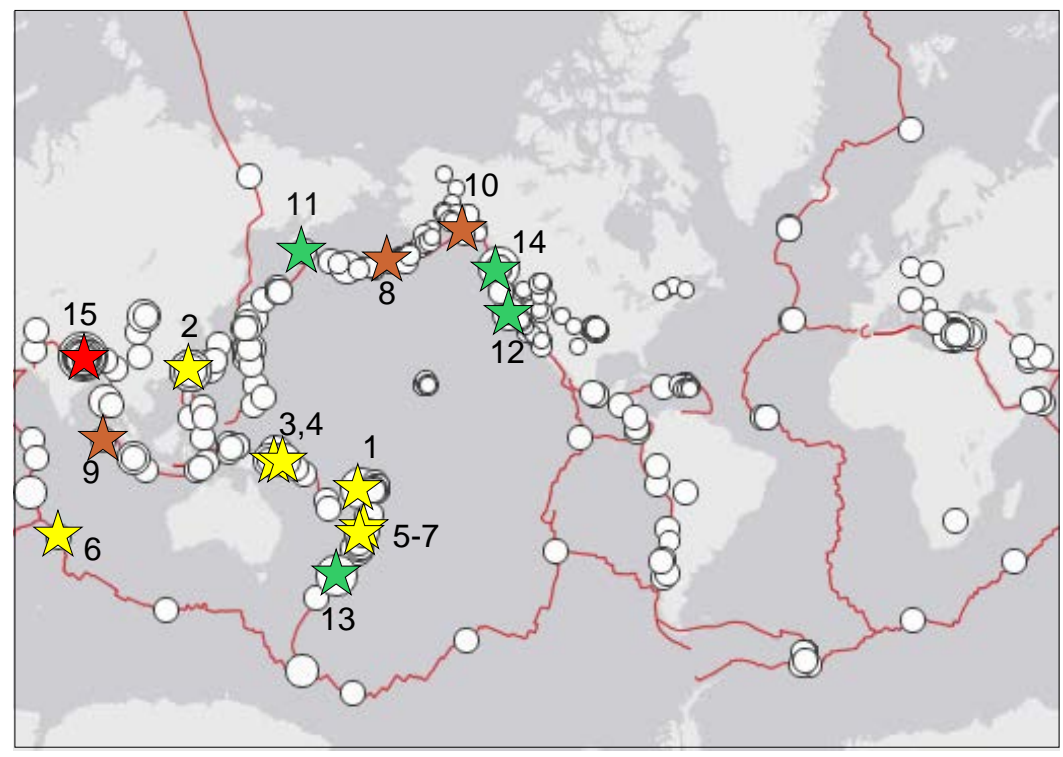

Figure 8. Earthquake in Nepal. Earthquakes' epicenters in the upper branching structure and TP. 


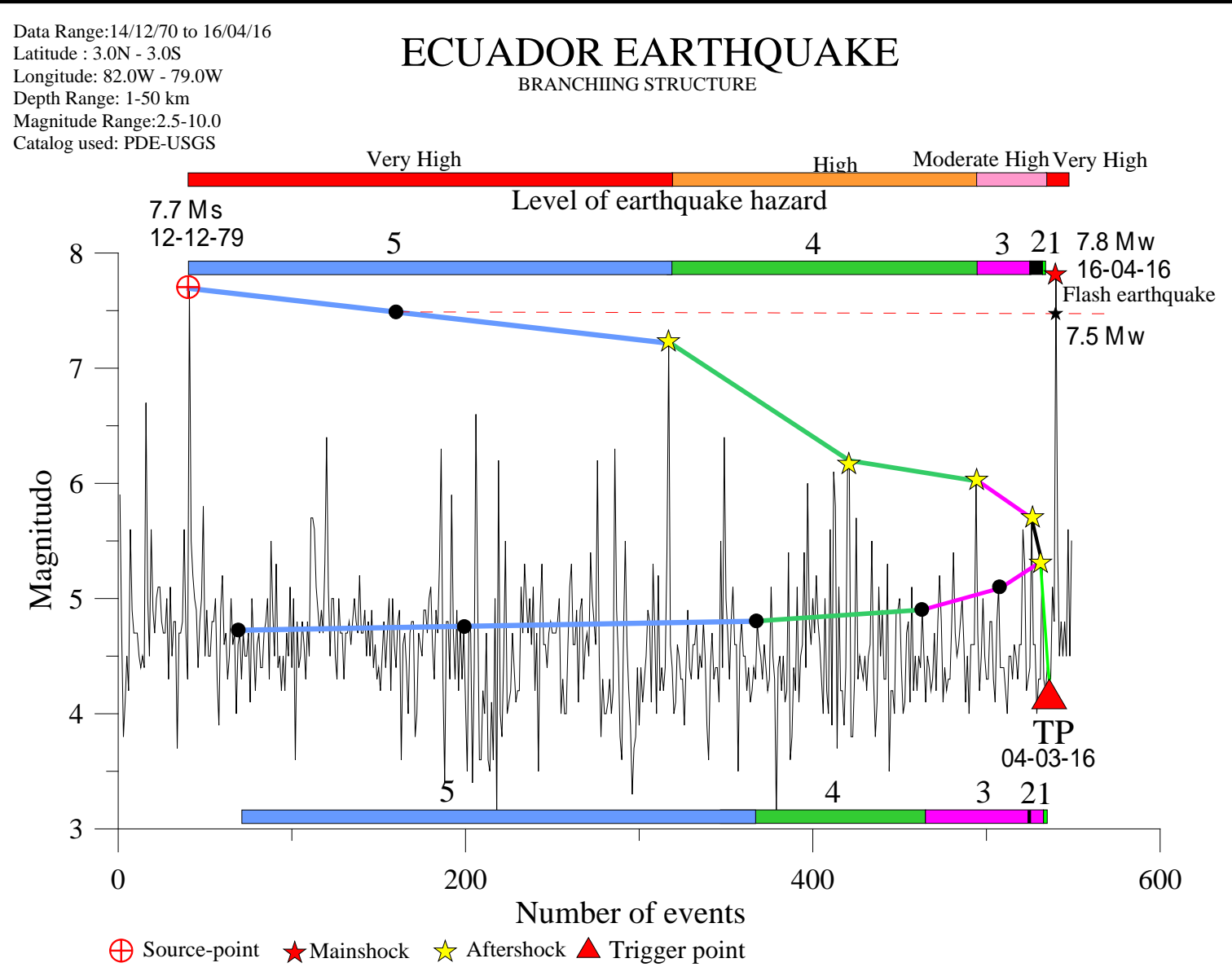

Figure 9. Ecuador earthquake. Branching structures and hazard classes.

branch of the same order in the lower one.

For example, Figure 9, relative to the Ecuador earthquake's seismic sequence, shows how, after the formation of a fifth order seismic branch in the lower branching structure, a seismic branch of the same order has formed in the upper branching structure. Then a new fifth order seismic branch in the lower branching structure has formed, followed, in time, by the formation of a fourth order rod in the upper structure (seismic branches alternating process).

Usually, this developmental process ends with the convergence of a third order seismic branch in the lower branching structure with a second order seismic branch in the upper branching structure, followed by the TP formation. The repetition of seismic branches of the same order during the branching structures developmental process is suggestive of a seismic delay in the ongoing energy accumulation stage.

Table 5 shows the formation order of seismic branches in upper and lower branching structures and the seismic sequence's TP of the Ecuador's earthquake.

The upper branching structure's hazard level from the point source onward varies from very high to moderately high, while from the TP on, the hazard level returns to very high values. The energy release stage was "Flash earthquake"-type [12], with a 
Data Range:29/05/05 to 12/05/15

Latitude : $32 \mathrm{~N}-26 \mathrm{~N}$

Longitude: $88.0 \mathrm{E}-81.0 \mathrm{E}$

Depth Range: 1-50 km

Magnitude Range:2.5-10.0

Catalog used: PDE-USGS

NEPAL EARTHQUAKE
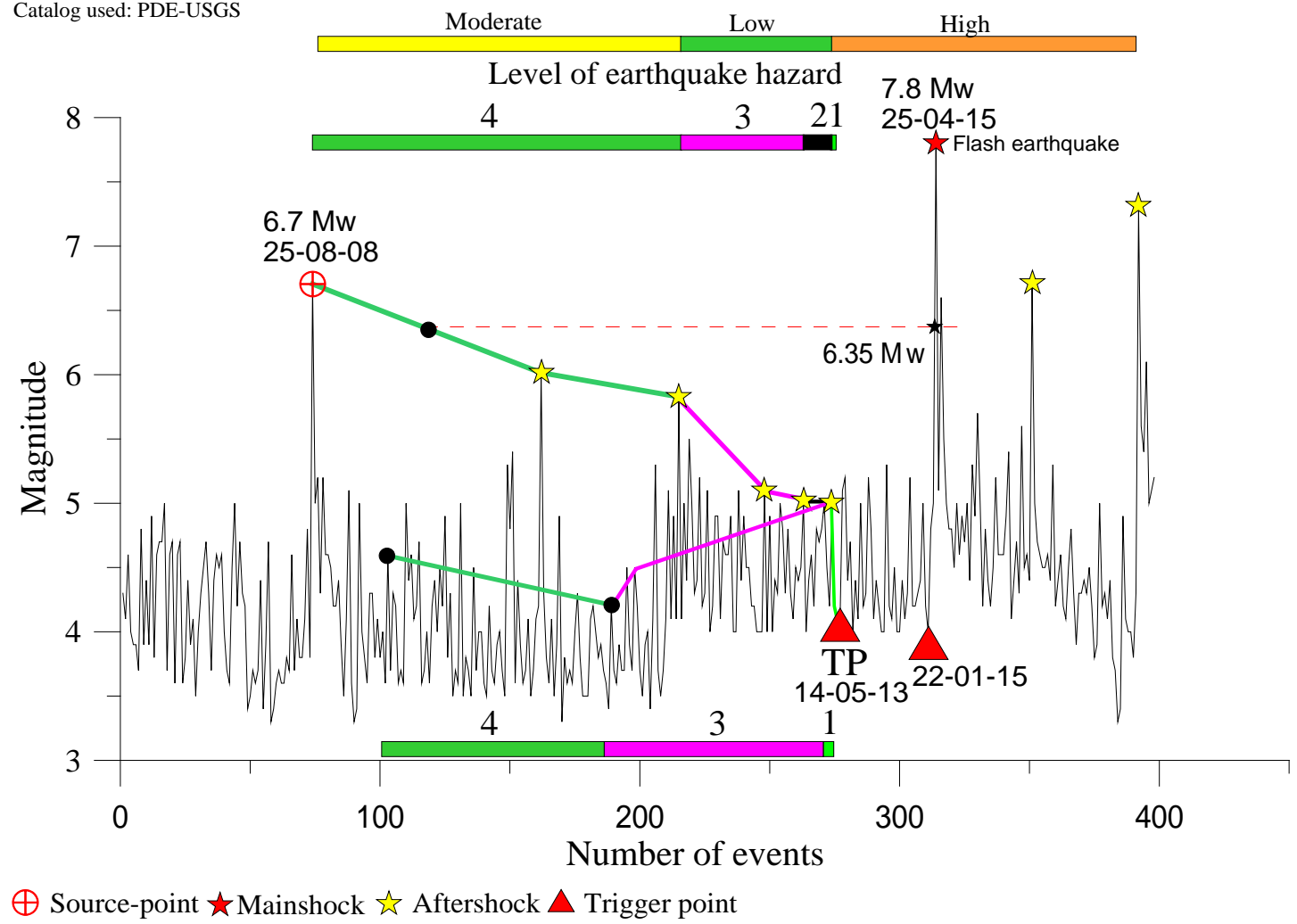

Figure 10. Earthquake in Nepal. Branching structures and hazard classes.

delay between the TP and the mainshock approximately of 44 days.

A similar trend is shown in the seismic sequence preceding the Nepal earthquake, on 25 April 2015 (Figure 10) where branching structures started from a fourth order branch and ended with the convergence of the third order branches with a second order one in the upper branching structure. The trigger point was formed on 14 May 2013 while the warning signs preceding the mainshock, generated by a DB-3SE microstructure, appeared on 22 January 2015 [13]. The delay between the TP and the mainshock was about 23 months, whereas that between the trigger point and the mainshock was approximately 3 months. The upper branching structure's hazard level after the TP decreased from moderate to low up, then returned to high values. The energy release stage was "Flash earthquake"-type.

Figure 11 shows the branching structure of the L'Aquila earthquake, occurred on 6 April 2009. We note a first upper branching structure with a point source that has formed on 15/08/1998, consisting of 5 developmental stages and an early convergence of the lower branching structure. The TP formed on 10 July 2007 was followed by a 4.0 $\mathrm{M}_{\mathrm{L}}$ magnitude seismic event that generated a second, abnormal fourth order branching structure, with a TP formed on 15/02/2009. The energy release stage was "Progressive 


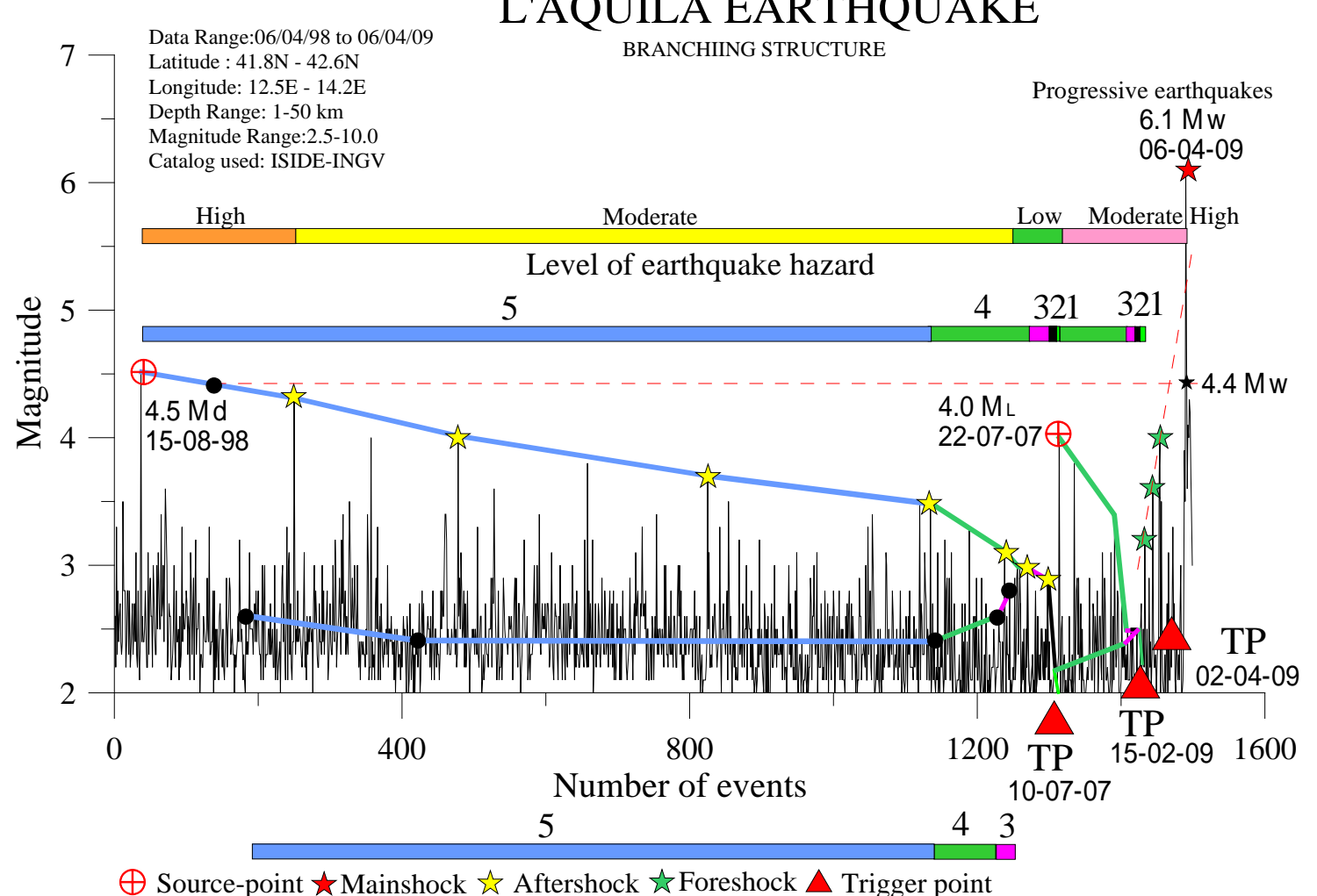

Figure 11. L'Aquila's earthquake. Branching structures and hazard classes.

earthquakes"-type, with the last trigger point generated on 02/04/2009. The delays between the first and the second TP compared to the mainshock were approximately 21 months (duration of the whole energy release stage) and 46 days, respectively, while the delay between the last TP and the mainshock was around 4 days.

The upper branching structure hazard level shows a decreasing trend from high to low up to the first TP, while during the energy release stage, it increased from moderate to potentially moderate-high if we consider the trendline joining the earthquakes the energy release stage.

Figure 12 shows the branching structures of the earthquake occurred in Emilia on 20 May 2012. The point source from which a fourth order upper branching structure has developed, has formed on 15/10/1996, while the TP was generated on 21/09/1997.

The energy release stage that followed was "Progressive earthquakes"-type with the last strongest earthquake, featuring a magnitude of $4.5 \mathrm{Md}$, recorded on 18/06/2000. This event is a second point source that generated a second third order upper branching structure and a TP that has formed on 22/02/2008.

The energy release stage consisted of two first order foreshocks of $4.5 \mathrm{Mw}$ and 4.9 Mw magnitude respectively and a second order foreshock of $4.0 \mathrm{Md}$ magnitude, recorded on 19/05/2012. The second order foreshock was preceded by a warning signal that was generated on $01 / 03 / 2012$. The delay between the second TP and the mainshock 


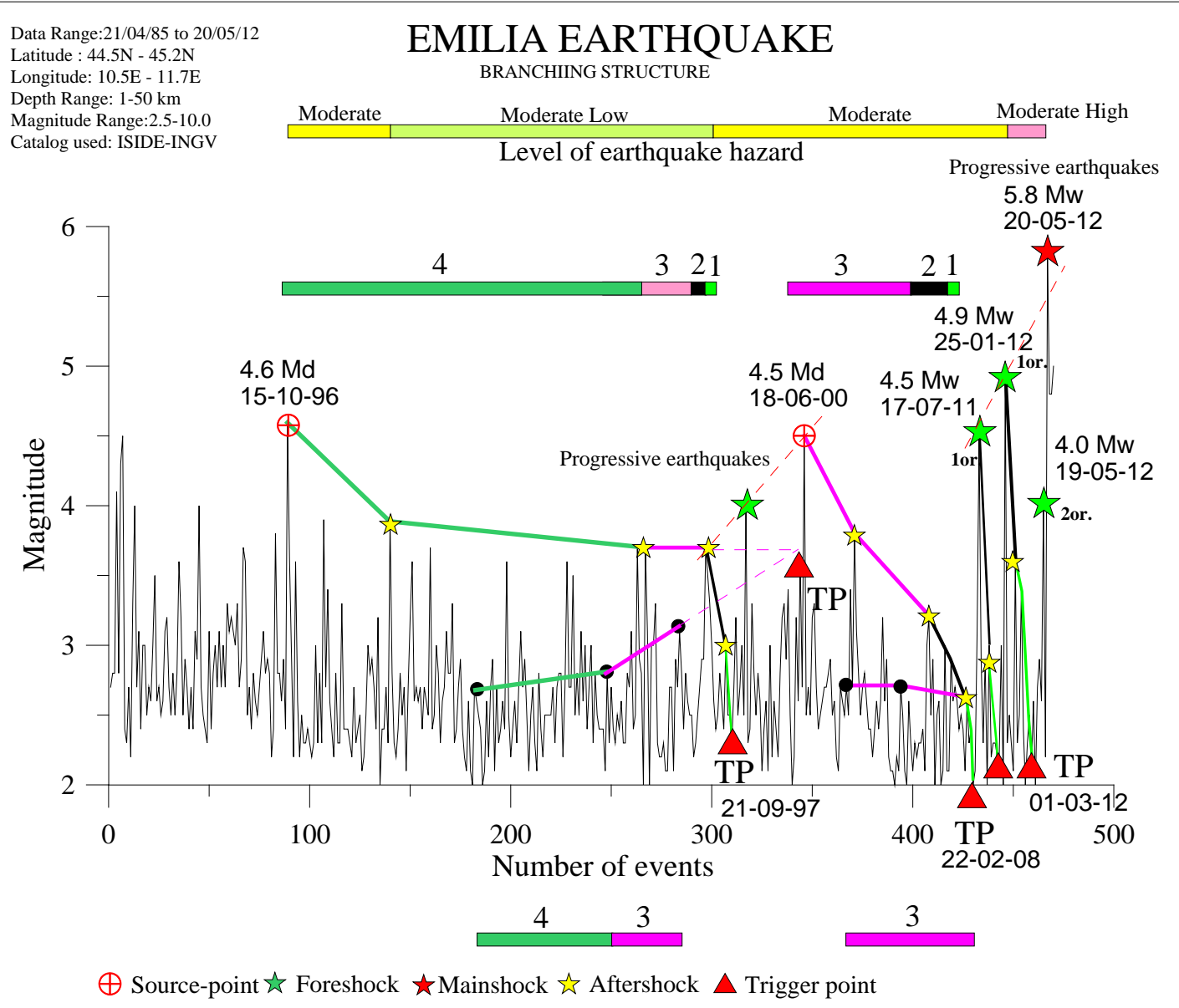

Figure 12. Earthquake in Emilia. Branching structures and hazard classes.

Table 5. Development of branching structures.

\begin{tabular}{|c|c|}
\hline Branching structure Less & Branching structure Top \\
\hline $5 \longrightarrow$ & 5 \\
\hline 5 & $\longleftarrow 5$ \\
\hline $5 \longrightarrow$ & 4 \\
\hline 4 & -4 \\
\hline $4 \longrightarrow$ & 4 \\
\hline 3 & -4 \\
\hline $3 \longrightarrow$ & 3 \\
\hline 3 & $\leftarrow$ \\
\hline $2 \longrightarrow$ & 4 \\
\hline & 1 \\
\hline & $\mathrm{TP}$ \\
\hline
\end{tabular}

was approximately 4 years and three months (duration of the whole energy release stage), the delay between the last TP on 01/03/2012 and the mainshock was about 80 
days, while the delay between the second order foreshock and the mainshock was one day.

The upper branching structure hazard level remained moderate/moderate low until the mainshock and then became moderately high.

\section{Conclusions}

By using the nodes of upper and lower branched structures' seismic branches, we have proposed new approaches to define a classification of the hazard levels reached by the upper branched structure during its development. This classification plays a crucial role in determining the hazardousness of the energy release phase that is triggered following the TP formation.

In fact, the upper and lower branched structures, in the last part of their development, show a convergence of branches of the same order with a lower order one, which is an important warning signal that usually precedes a strong earthquake and determines a warning sign of the sequence's hazardousness and its development.

Analyzing the upper branched structure's temporal and spatial changes both on global and local scale, it appears that they are adequate enough to assume a long-distance interaction between the various earthquakes.

These interactions should, however, be linked both to the static stress changes and the passage of seismic waves from the most energetic earthquakes. These can generate transient stresses in the earth's crust, thus triggering earthquakes far from the original earthquake source.

We also believe that recurrence rates that can be observed in the branching structure's first order seismic branches most likely reflect the different tectonic loading rates of the seismic regions concerned.

Conversely, in the last stages, the decrease in the recurrence rates is probably due to a very high tectonic load, where small shocks can trigger the energy release stage.

\section{References}

[1] Pollitz, F.F. and Johnston, M.J.S. (2006) Direct Test of Static Stress versus Dynamic Stress Triggering of Aftershocks. Geophysical Research Letters, 33, L15318. http://dx.doi.org/10.1029/2006gl026764 https://profile.usgs.gov/myscience/upload_folder/ci2010Nov2222030742871152.pdf

[2] Riga, G. and Balocchi, P. (2016) Short-Term Earthquake Forecast with the Seismic Sequence Hierarchization Method. Open Journal of Earthquake Research, 5, 79-96.

http://dx.doi.org/10.4236/ojer.2016.52006 http://www.scirp.org/Journal/PaperInformation.aspx?PaperID=66332

[3] Harris, R.A. (1998) Introduction to Special Section: Stress Triggers, Stress Shadows, and Implications for Seismic Hazard. Journal of Geophysical Research: Solid Earth, 103, 24347-24358. http://dx.doi.org/10.1029/98jb01576

[4] Stein, R.S. (1999) The Role of Stress Trasfert in Earthquake Occurrence. Nature, 402, 605-609. http://dx.doi.org/10.1038/45144

[5] King, G.C.P. and Cocco, M. (2000) Fault Interaction by Elastic Stress Change: New Clues from Earthquake Sequences. Advances in Geophysics, 44, 1-38. 
http://dx.doi.org/10.1016/S0065-2687(00)80006-0

[6] Stein, R.S., Barka, A.A. and Dieterich, J.H. (1997) Progressive Failure on the North Anatolian Fault Since 1939 by Earthquake Stress Triggering. Geophysical Journal International, 128, 594-604. http://dx.doi.org/10.1111/j.1365-246X.1997.tb05321.x

[7] Brodsky, E.E. and van der Elst, N.J. (2014) The Uses of Dynamic Earthquake Triggering. Annual Review of Earth and Planetary Sciences, 42, 317-339. http://dx.doi.org/10.1146/annurev-earth-060313-054648

[8] Freed, A.M. (2005) Earthquake Triggering by Static, Dynamic, and Postseismic Stress Transfer. Annual Review of Earth and Planetary Sciences, 33, 335-367.

http://dx.doi.org/10.1146/annurev.earth.33.092203.122505

http://www.annualreviews.org/doi/abs/10.1146/annurev.earth.33.092203.122505?journalCo de=earth

[9] Delorey, A.A., Chao, K., Obara, K. and Johnson, P.A. (2015) Cascading Elastic Perturbation in Japan Due to the $2012 M_{w} 8.6$ Indian Ocean Earthquake. Science Advances, 1, e1500468. http://dx.doi.org/10.1126/sciadv.1500468

[10] Lin, J. and Stein, R.S. (2004) Stress Triggering in Thrust and Subduction Earthquakes and Stress Interaction between the Southern San Andreas and Nearby Thrust and Strike-Slip Faults. Journal of Geophysical Research: Solid Earth, 109, B02303.

http://dx.doi.org/10.1029/2003jb002607

[11] Belardinelli, M.E., Bizzarri, A. and Cocco, M. (2002) Earthquake Triggering by Static and Dynamic Stress Changes. Journal of Geophysical Research: Solid Earth, 108, 2135. http://www.bo.ingv.it/ bizzarri/Download/Productions/JGR_2003-1_Paper.pdf

[12] Riga, G. and Balocchi, P. (2016) Seismic Sequence Structure and Earthquakes Triggering Patterns. Open Journal of Earthquake Research, 5, 20-34.

http://dx.doi.org/10.4236/ojer.2016.51003 http://www.scirp.org/Journal/PaperInformation.aspx?PaperID=63538

[13] Riga, G. and Balocchi, P. (2016) How to Predict Earthquakes with Microsequences and Reversed Phase Repetitive Patterns. Open Journal of Earthquake Research, 5, 153-164. http://dx.doi.org/10.4236/ojer.2016.53012

Submit or recommend next manuscript to SCIRP and we will provide best service for you:

Accepting pre-submission inquiries through Email, Facebook, LinkedIn, Twitter, etc.

A wide selection of journals (inclusive of 9 subjects, more than 200 journals)

Providing 24-hour high-quality service

User-friendly online submission system

Fair and swift peer-review system

Efficient typesetting and proofreading procedure

Display of the result of downloads and visits, as well as the number of cited articles

Maximum dissemination of your research work

Submit your manuscript at: http://papersubmission.scirp.org/

Or contact ojer@scirp.org 